\title{
IMPLEMENTASI FRAMEWORK IONIC DAN LAYANAN GOOGLE MAPS DALAM APLIKASI SISTEM INFORMASI GEOGRAFIS
}

\author{
Dwi Wijonarko1, Betta Wahyu Retna Mulya² \\ 1,Teknik Informatika, Politeknik Kota Malang,,2,Teknik Informatika, Politeknik Kota Malang \\ Jalan Raya Tlogowaru No 3 Kedungkandang Kota Malang Jawa Timur, 65133 \\ 1d.wijonarko@poltekom.ac.id, 2betta.wahyu@poltekom.ac.id
}

\begin{abstract}
This research aims to implement a hybrid framework based mobile application development using the IONIC Framework, which is combined with the application of the Google Map library. The application built functions to display spatial data in the form of geographic information systems. The data shown is the location of public schools in Malang starting from elementary school to high school and vocational school levels. Data displayed includes school information, addresses and contacts displayed on a digital map, so that you can see the location and distance from the user's current location. The use of the IONIC Framework aims to enable applications to run on Android and iOS mobile operating systems. The hope is that the application can cover a wide range of users and can be utilized to the maximum extent possible to search for school data in the city of Malang.
\end{abstract}

Keywords : Ionic, Hybrid Application, Geographic Information System, Google Maps

\begin{abstract}
Abstrak
Pengembangan penelitian ini bertujuan untuk melakukan implementasi pengembangan aplikasi mobile berbasis framework hybrid menggunakan IONIC Framework, yang digabungkan dengan penerapan pustaka Google Map. Aplikasi yang dibangun berfungsi menampilkan data spasial dalam bentuk system informasi geografis. Data yang ditampilkan adalah lokasi sekolah negeri di Kota Malang mulai jenjang SD sampai tingkat SMA dan SMK. Data yang ditampilkan meliputi keterangan sekolah, alamat dan kontak yang ditampilkan dalam peta digital, sehingga bisa terlihat posisi lokasi dan jarak dari lokasi pengguna saat ini. Penggunaan IONIC Framework bertujuan agar aplikasi bisa dijalankan dalam system operasi mobile Android dan iOS. Harapannya adalah aplikasi bisa mencakup berbagai kalangan pengguna dan bisa dimanfaatkan semaksimal mungkin untuk mencari data-data sekolah yang ada di kota Malang.
\end{abstract}

Kata kunci : Ionic, Hybrid Application, Sistem Informasi Geografis,Google Maps

\section{PENDAHULUAN}

Sistem informasi geografis adalah sistem informasi yang digunakan untuk memasukkan, menyimpan, memanggil kembali, mengolah, menganalisa, dan menghasilkan data bereferensi geografis atau geospatial, untuk mendukung pengambilan keputusan dalam suatu perencanaan (Budiyanto, 2016).

Sistem Informasi Geografis (SIG) mengorganisasikan dan memanfaatkan data dari peta digital yang tersimpan dalam basis data. Dalam SIG, dunia nyata dijabarkan dalam data peta digital yang menggambarkan posisi dari ruang (space) dan klasifikasi, atribut data, dan hubungan antaritem data. Kerincian data dalam SIG ditentukan oleh besarnya satuan pemetaan terkecil yang dihimpun dalam basis data. Dalam bahasa pemetaan kerincian itu tergantung dalam skala peta dan dasar acuan 
geografis yang disebut sebagai peta dasar. (Budiman, 1999)

SIG di Indonesia telah digunakan oleh banyak instansi baik pemerintah maupun swasta untuk mendukung perencanaan dan pembuatan keputusan dalam unit organisasinya.

SIG masih mempunyai beberapahal yang perlu dikembangkan sepertistandard data, pendidikan, kualitasdata dan sebagainya, agar diperolehhasil yang optimal. Seiring berkembangnya teknologi, pengoperasian SIG tidak lagi terbatas pada komputer dengan skala besar, perangkat bergerak pintar (smartphone) juga sudah menerapkan SIG dalam aplikasinya, misalnya menentukan titik pelanggan, toko serta layanan lainnya.

Pada saat ini, dinas pendidikan membuat aturan penerimaan siswa baru berbasis zonasi, yang berarti jarak tempat tinggal dengan sekolah menjadi bobot utama penerimaan calon siswa. Dengan adanya system ini, diharapkan calon siswa mampu memilih dan melihat posisi lokasi tempat tinggal dengan lokasi sekolah yang diminati, dan memudahkan pemilihan sekolah yang dituju.

\section{TINJAUAN PUSTAKA DAN TEORI}

\section{A. Tinjauan Pustaka}

Harison dan Kurniawan dalam penelitiannya yang berjudul Aplikasi Sistem Informasi Geografis Produksi Padi dan Cabe di Kabupaten Lima Puluh Berbasis Android membahas tentang pengembangan sistem informasi geografis berbasis aplikasi Android menggunakan Bahasa pemrograman Java. Kabupaten Lima Puluh Kota merupakan salah satu daerah produksi padi dan cabe. Saat ini pemasaran hasil produksi hanya di antarkan ke pasar terdekat, pada hal dengan sentuhan sistem informasi geografis maka hasil panen petani akan dicari oleh marketing ke kebun langsung, karna kebutuhan akan padi dan cabe ini sangat di cari pasar. Aplikasi Sistem informasi geografis produksi padi dan cabe berbasis android dirancang dengan menggunakan bahasa pemograman java dan database MySqLite dan untuk GIS memanfaatkan google maps dan langsung mengambil titik koordinat pada setiap Nagari atau Desa yang ada pada Kabupaten Limapuluh Kota.

Padmadiningrat, Bagus Kadek dkk menulis dalam artikelnya Aplikasi Sistem Informasi Geografis (SIG) dan Penginderaan Jauh untuk Pemetaan Daerah Penangkapan Ikan Tuna Mata Besar di Selatan Jawa dan Bali. Tujuan dari penelitian ini adalah untuk mengetahui hubungan antara suhu permukaan laut dan klorofil-a dengan jumlah tangkapan tuna mata besar di perairan selatan Jawa dan Bali, dan memetakan area penangkapan tuna mata besar di perairan selatan Jawa dan Bali. Metode yang digunakan adalah analisis regresi polinomial orde dua untuk mengetahui pengaruh suhu permukaan laut dan klorofil-a dengan jumlah tangkapan tuna mata besar serta analisis korelasi untuk mengetahui hubungan suhu permukaan laut dan klorofil-a dengan jumlah tangkapan tuna bigeye. Suhu permukaan laut dan klorofil-a terkait dengan jumlah tangkapan tuna mata besar. Hasil analisis menunjukkan hubungan yang kuat antara suhu permukaan laut dan klorofil-a dengan jumlah tangkapan tuna mata besar.(Padmaningrat , Karang , \& As-syakur , 2017)

Artikel yang ditulis Yulius dan Arifin yang berjudul Analisis Sistem Informasi Geografis (SIG) untuk Potensi Wisata Pantai di Kota Makasar, Provinsi Sulawesi Selatan Tujuan dari penelitian ini adalah untuk mengidentifikasi potensi wisata oastal di kota makassar menggunakan analisis spasial GIS. Metode yang digunakan dalam penelitian ini adalah analisis spasial menggunakan SIG. Hasilnya menunjukkan bahwa pantai Makassar dibagi menjadi tiga jenis, yaitu: (1) pantai berpasir, (2) pantai bakau dan (3) pantai reklamasi. Jenis-jenis pantai tersebut dapat direkomendasikan untuk beberapa kegiatan pariwisata seperti: (1) pantai berpasir: snorkeling, olahraga pantai, bola voli pantai dan sepak bola pantai, piknik pantai, berenang, berjemur, berselancar, (2) pantai bakau: studi lapangan dan (3) pantai reklamasi: memancing, berjalan dan jogging di pantai. Kota Makassar, sebagai ibu kota Provinsi Sulawesi Selatan, memiliki potensi sumber daya alam dengan pantai berpasir yang agak landai, dari utara ke selatan. Tujuan dari penelitian ini adalah untuk mengidentifikasi potensi wisata oastal di kota makassar menggunakan analisis spasial GIS. Metode yang digunakan dalam penelitian ini adalah analisis spasial menggunakan SIG. Hasilnya menunjukkan bahwa pantai Makassar dibagi menjadi tiga jenis, yaitu: (1) pantai berpasir, (2) pantai bakau dan (3) pantai reklamasi. Jenis-jenis pantai tersebut dapat direkomendasikan untuk beberapa kegiatan pariwisata seperti: (1) pantai berpasir: snorkeling, olahraga pantai, bola voli pantai dan sepak bola pantai, piknik pantai, berenang, berjemur, berselancar, (2) pantai bakau: studi lapangan dan (3) pantai reklamasi: memancing, 
berjalan, dan jogging di pantai. (Yulius \& Taslim, 2014)

Syahputra dkk, menulis penelitian tentang RANCANG BANGUN SISTEM INFORMASI GEOGRAFIS PEMETAAN DAERAH RAWAN KRIMINALITAS DIKOTA MATARAM BERBASIS WEB yang bertujuan untuk membangun sistem yang dapat memberikan informasi tentang lokasi, pemetaan dan membantu orang untuk mengetahui titik distribusi kriminalitas di kota Mataram. Plaform yang digunakan pada penelitian ini adalah aplikasi berbasis web menggunakan codeigniter dan Google Map API.(SYAHPUTRA, WIDIARTHA, \& ZUBAIDI, 2019). Sedangkan Bagye dkk dalam artikelnya SISTEM INFORMASI GEOGRAFIS PERSEBARAN MASYARAKAT MISKIN (DAMASKIN) DI DESA MONGGAS BERBASIS WEB mengembangkan sistem informasi geografis yang difungsikan menampilkan pendataan masyarakat miskin di daerah tersebut. Dibangun sistem informasi geografis Persebaran masyarakat miskin desa Monggas berbasis web. Metode yang digunakan dalam merancang sistem informasi geografis Persebaran masyarakat miskin ini adalah System Development Life Cycle (SDLC). Ada empat tahap dalam pnelitian ini yaitu tahap analisis sistem, tahap perancangan sistem, tahap uji coba, dan tahap pengujian sistem.(BAGYE, HAQIQI, \& ASHARI, 2019)

\section{B. Sistem Informasi Geografis}

Sistem Informasi Geografis (bahasa Inggris: Geographic Information System disingkat GIS) adalah sistem informasi khusus yang mengelola data yang memiliki informasi spasial (bereferensi keruangan), atau dalam arti yang lebih sempit adalah sistem komputer yang memiliki kemampuan untuk membangun, menyimpan, mengelola dan menampilkan informasi berefrensi geografis, misalnya data yang diidentifikasi menurut lokasinya, dalam sebuah database. (Harison \& Kurniawan, 2017)

Menurut sumber lain GIS adalah suatu sistem informasi yang dirancang untuk bekerja dengan data yang bereferensi spasial atau berkoordinat geografi, atau dengan kata lain suatu GIS adalah suatu sistem basis data dengan kemampuan khusus untuk menangani data yang bereferensi keruangan (spasial) bersamaan dengan seperangkat operasi kerja(B \& Wiradisastra, 2000).
Disamping itu, GIS juga dapat menggabungkan data, mengatur data dan melakukan analisis data yang akhirnya akan menghasilkan keluaran yang dapat dijadikan acuan dalam pengambilan keputusan pada masalah yang berhubungan dengan geografis.

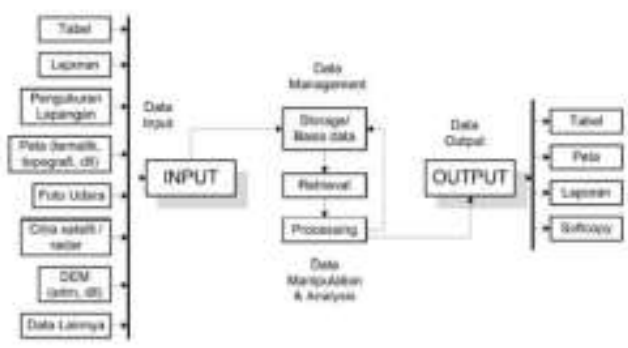

Gambar 1. Ilustrasi Data SIG

\section{Hybrid Mobile Application}

Aplikasi pada perangkat bergerak, dibangun menggunakan Bahasa pendukung system operasinya. Pada sistem operasi Android, aplikasi dibangun menggunakan Bahasa Java atau Kotlin, sedangkan pada sistem operasi iOS dibangun menggunakan Bahasa Swift atau Objective C.

Keterbatasan pemilihan bahasa pemrograman tersebut, dapat sedikit diminimalisir menggunakan aplikasi hibrida, yaitu dengan menggunakan teknologi web yang diubah menjadi platform sistem operasi tertentu. Dengan aplikasi hybrid ini, pengembang dapat membuat aplikasi multiplatform dengan cepat dan efisien.(Griffith, 2019)

\section{Ionic Framework}

Ionic Framework adalah kerangka kerja yang digunakan untuk pengembangan antar muka aplikasi yang dibuat dengan HTML, CSS, dan JavaScript yang dapat diubah menjadi aplikasi mobile hibrid. Selain komponen antarmuka aplikasi, Ionic Framework memilik fungsi yang lebih luas seperti Command Line Interface (CLI) dan serangkaian layanan tambahan seperti Ionic View dan Ionic Creator.

Ionic merupakan kombinasi dari beberapa teknologi yang bekerja bersama untuk membuat aplikasi hybrid. Ionic berada pada lapisan teratas antar muka aplikasi didukung framework javascript Angular, sedangkan untuk mengolah menjadi aplikasi mobile, digunakan Cordova penghubung dan menyediakan kemampuan untuk berkomunikasi dengan perangkat bergerak layaknya aplikasi yang dibangun menggunakan bahasa native. 


\section{METODOLOGI PENELITIAN}

Penelitian ini terrmasuk jenis penelitan R\&D (Research and Development). Penelitian implementasi framework Ionic dan layanan Google Maps dalam aplikasi sistem informasi geografis tahapannya dilihat dalam gambar berikut

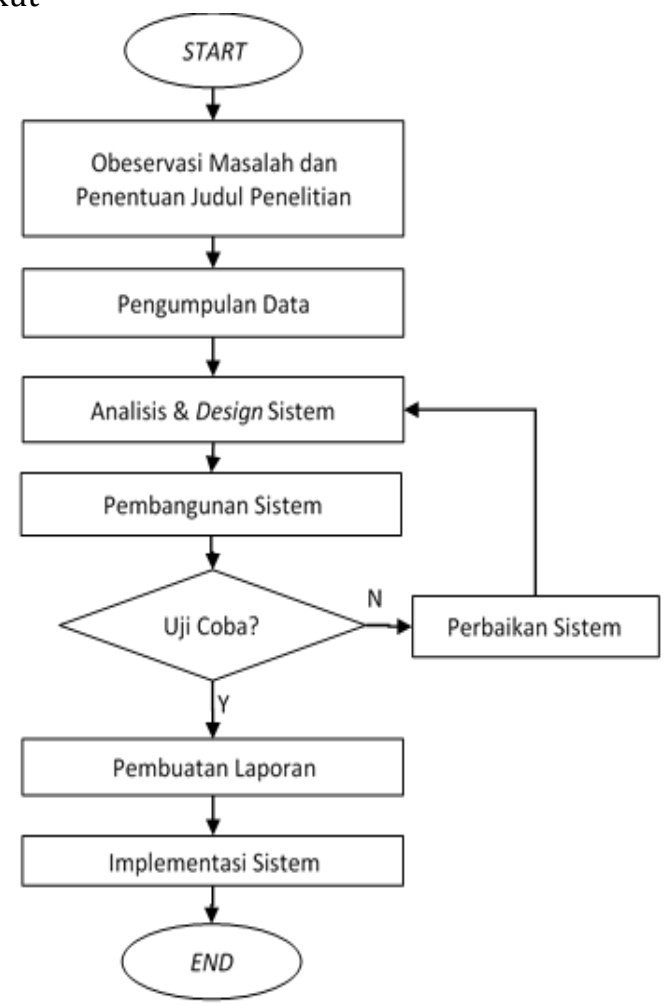

Gambar 2. Tahapan Penelitian

Penelitian ini menggunakan model penelitian kuantitatif dan studi kasus. Penelitian kuantitatif adalah suatu proses menemukan pengetahuan yang menggunakan data berupa angka sebagai alat menganalisis keterangan mengenai apa yang ingin diketahui(Kasiram, 2010).

\section{HASIL DAN PEMBAHASAN}

Hasil dari penelitian ini adalah sebuah aplikasi mobile Android, yang memiliki fungsi menampilkan data sekolah dasar hingga menengah menggunakan layanan Google Maps. Aplikasi ini dibangun menggunakan platform Ionic dan Bahasa Angular JS.

Data lokasi sekolah yang ditampilkan, didapatkan dari layanan Antar muka Pemrograman Aplikasi (API) yang beralamatkan di https://gis.poltekom.ac.id/. Pada halaman API tersebut terdapat tautan yang menampilkan data sekolah dalam bentuk JSON. Data yang ditampilkan selain data Nama sekolah dan Alamat, juga lokasi sekolah dalam bentuk titik koordinat. Contoh hasil JSON yang ditampilkan adalah sebagai berikut :

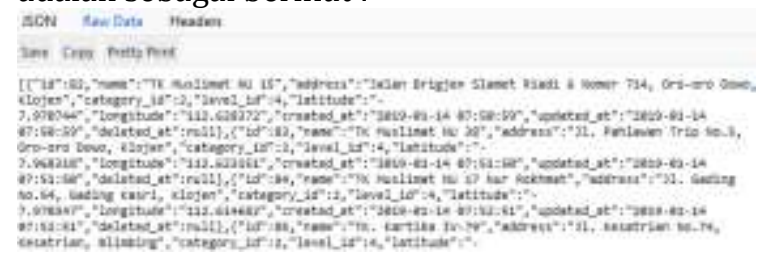

Untuk tautan yang digunakan adalah :

1. https://gis.poltekom.ac.id/tk untuk data sekolah tingkat Sekolah Kanak-kanak

2. https://gis.poltekom.ac.id/sd untuk data sekolah tingkat Sekolah Dasar

3. https://gis.poltekom.ac.id/smp untuk data sekolah tingkat Sekolah Menengah Pertama

4. https://gis.poltekom.ac.id/sma untuk data sekolah tingkat Sekolah Menengah Atas dan Kejuruan

5. https://gis.poltekom.ac.id/pt untuk data sekolah tingkat Perguruan Tinggi

Sedangkan untuk tampilan aplikasi yang dihasilkan adalah sebagai berikut

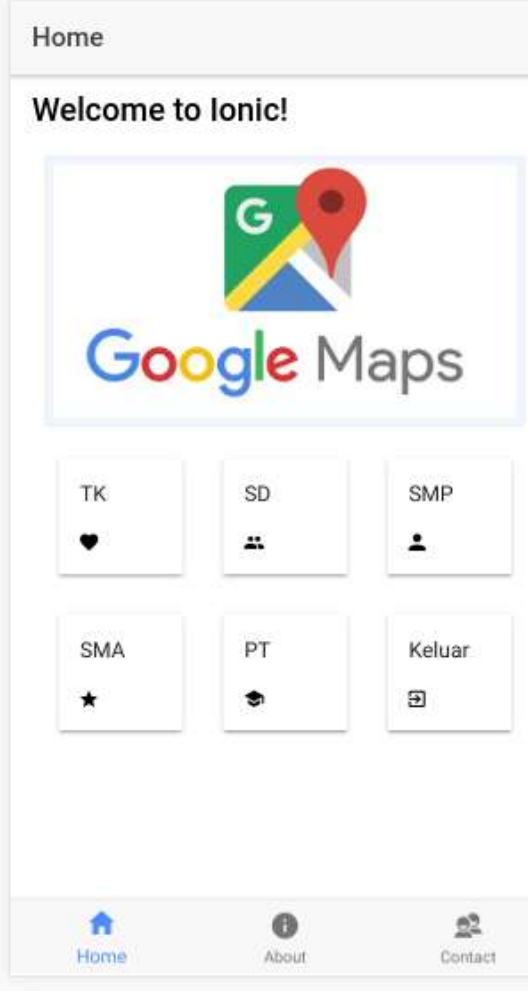

Gambar 3. Homepage Aplikasi 
Halaman awal berupa tautan menuju halaman selanjutnya. Tautan ini memisahkan data sekolah berdasarkan tingkatannya.

Untuk tingkat taman kanak-kanak, hasilnya adalah seperti ditunjukkan gambar 4. Marker bewarna biru menujukkan posisi lokasi pengguna saat ini, sedangkan marker sekolah ditandai dengan warna merah. Apabila marker dipilih, akan muncul nama sekolah dan keterangan jarak dari lokasi pengguna saat ini. Gambar 4 sampai dengan gambar 8 menujukkan perbedaan lokasi dari tiap tingkatan sekolah.

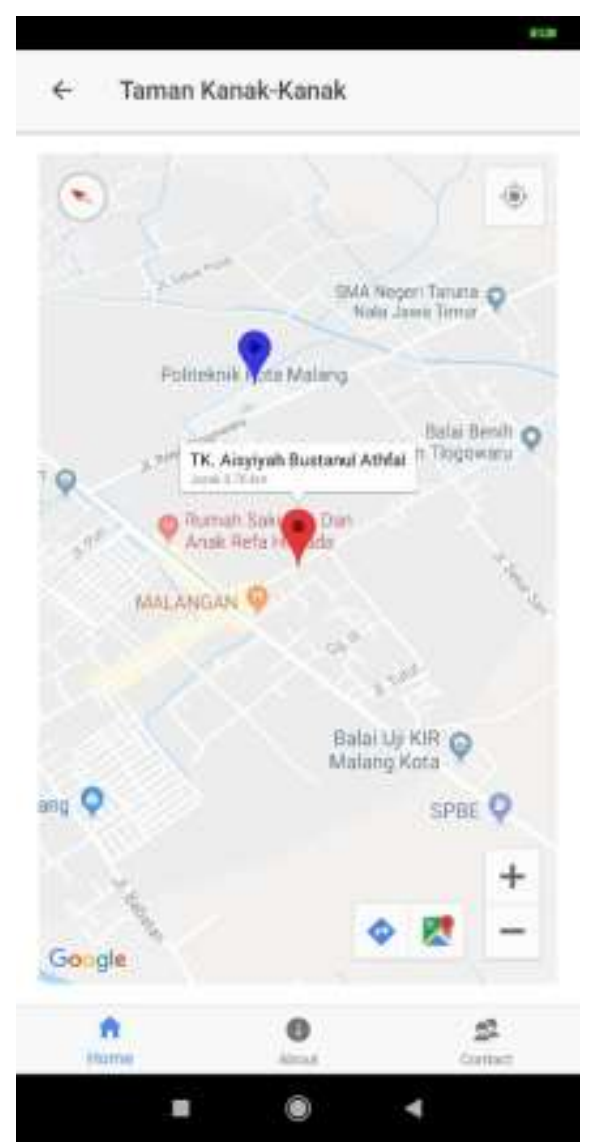

Gambar 4. Lokasi Taman kanak-kanak

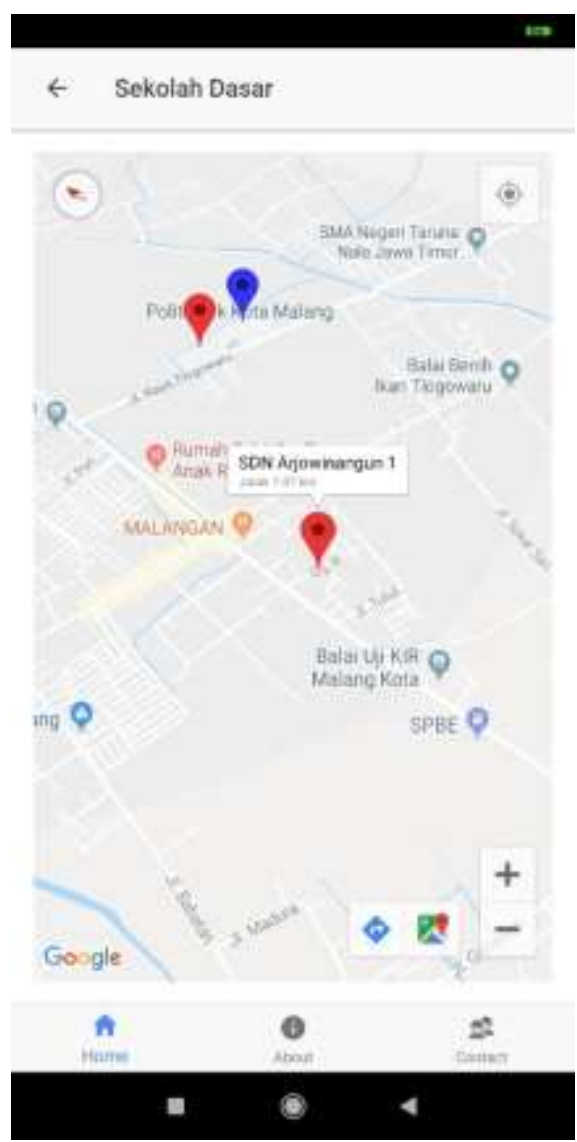

Gambar 5. Lokasi sekolah dasar

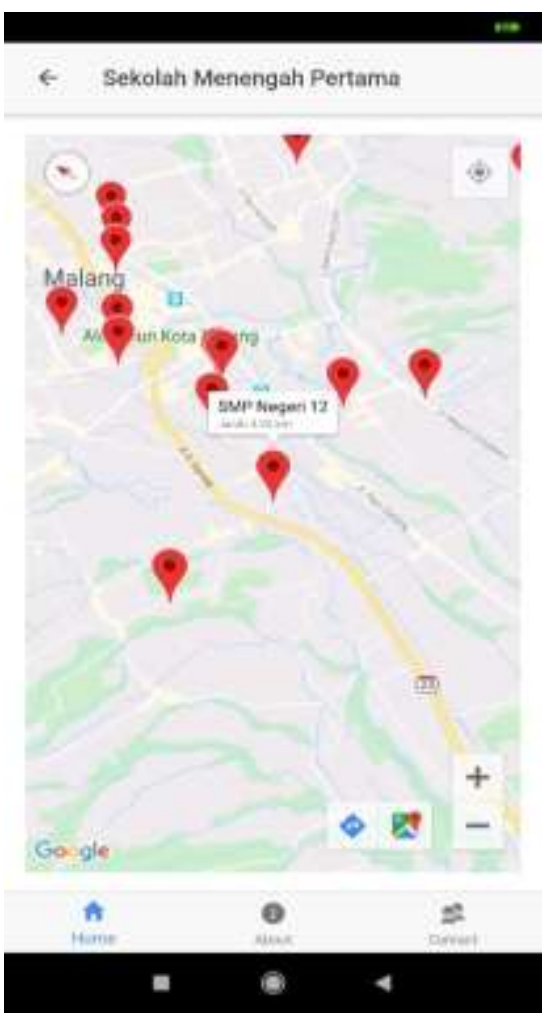

Gambar 6. Lokasi Sekolah Menengah Pertama 


\section{http://e-journal.stmiklombok.ac.id/index.php/misi}

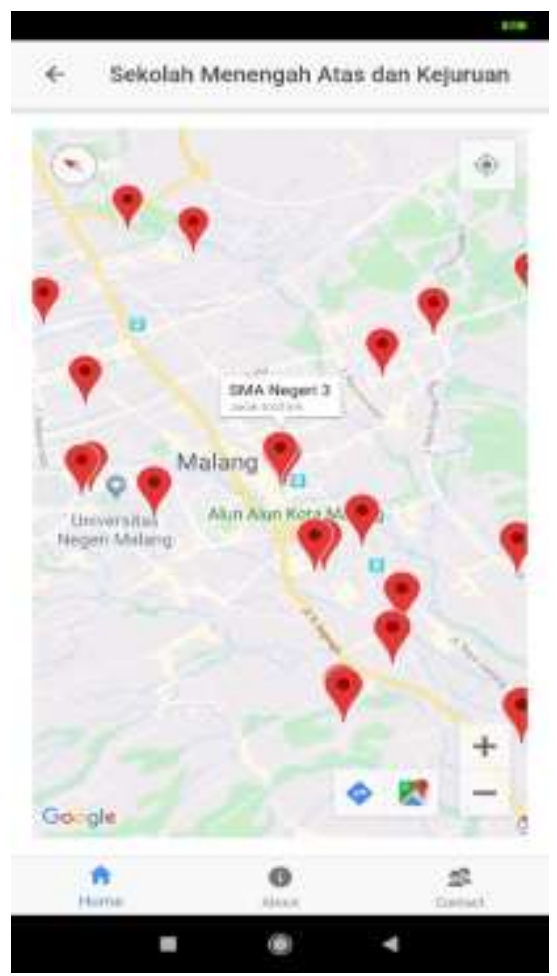

Gambar 7. Lokasi Sekolah Tingkat Menengah Atas

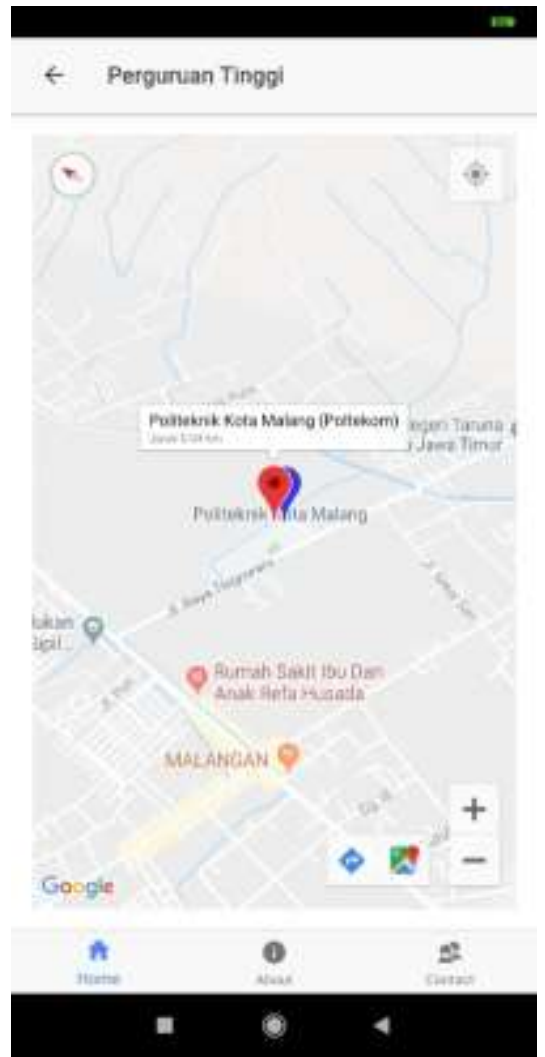

Gambar 8. Lokasi Perguruan Tinggi

\section{KESIMPULAN DAN SARAN}

Dari penelitian yang dilakukan dan tercipta aplikasi yang sudah dikembangkan, peneliti memberikan kesimpulan sebagai berikut :

1. Aplikasi sudah berjalan dengan baik, terbukti dengan sudah dilakukannya uji coba yang dilakukan.

2. Keakuratan deteksi lokasi dipengaruhi oleh berbagai factor antara lain sinyal GPS dan sinyal provider perangkat.

3. Pengkoleksian data lokasi sekolah, dilakukan dengan cara gabungan menggunakan cara konvensional dengan mengunjungi sekolah dan bantuan layanan Google Maps

4. Pengukuran jarak lokasi sekolah dengan pengguna, digunakan rumus jarak antar koordinat, sehingga tidak memperhitungkan rute jalan.

5. Framework Ionic mampu menyajikan aplikasi hybrid yang ringan dan mudah dalam pengembangannnya.

Saran untuk penelitian selanjutnya adalah dengan melengkapi data sekolah dan membangun aplikasi dalam format iOS, serta perhitungan jarak menggunakan route lalu lintas jalan raya.

\section{Daftar Pustaka}

[1] B, B., \& Wiradisastra, U. (2000). Sistem Informasi Geografi, Sarana Manajemen Sumberdaya. Bogor: Laboraturium Penginderaan Jauh dan Kartografi, Fakultas Pertanian, IPB.

[2] W. Bagye, L. Z. Haqiqi, and M. Ashari, "Sistem Informasi Geografis Persebaran Masyarakat Miskin (Damaskin) Di Desa Monggas Berbasis Web," J. Manaj. Inform. dan Sist. Inf., vol. 2, no. 2, p. 9, 2019, doi: 10.36595/misi.v2i2.99.

[3] Budiman. (1999). Menuju Industri Sistem Informasi Geografis Yang Andal. Jakarta: Lembaga Informasi Pembangunan dan Bisnis Indonesia (LIPBI).

[4] Budiyanto, E. (2016). Sistem Informasi Geografis dengan Quantum GIS. Yogyakarta: Penerbit Andi.

[5] Griffith, C. (2019, Februari 7). What Is Hybrid App Development. (Ionic) Dipetik November 8, 2019, dari 
https://ionicframework.com/resources/ar ticles/what-is-hybrid-app-development

[6] Harison, H., \& Kurniawan, F. (2017). Aplikasi Sistem Informasi Geografis Produksi Padi dan Cabe di Kabupaten Lima Puluh Berbasis Android. Jurnal Teknologi dan Sistem Informasi, 3, 43-50.

[7] Kasiram, M. (2010). Metodologi penelitian: Kualitatif-Kuantitatif. Malang: UIN-Maliki Press.

[8] Padmaningrat, K. B., Karang , I., \& Assyakur , A. (2017). Aplikasi Sistem Informasi Geografis (SIG) dan Penginderaan Jauh untuk Pemetaan Daerah Penangkapan Ikan Tuna Mata Besar di Selatan Jawa dan Bali . Journal of Marine and Aquatic Sciences, , 3, 70-83.

[9] Syahputra, e., widiartha, i. B., \& zubaidi, a. (2019). Rancang bangun sistem informasi geografis pemetaan daerah rawan kriminalitas dikota mataram berbasis Web . Jurnal Manajemen Informatika dan Sistem Informasi, 39 - 46.

[10] Yulius, Y., \& Taslim, A. (2014). Analisis Sistem Informasi Geografis (SIG) untuk Potensi Wisata Pantai di Kota Makasar, Provinsi Sulawesi Selatan. Tataloka, 3, 145-152.
[11] M. L. Hakim et al., "Pemanfaatan Teknologi Google Maps Api Untuk Aplikasi Pendetaksian Lokasi Rawan Kriminalitas Berbasis Android Kecamatan Praya Timur, Kabupaten Lombok Tengah,” JIRE (Jurnal Inform. Rekayasa Elektron., vol. 2, no. 1, pp. 52-59, 2019.

[12] Lombok, Khairul Imtihan-STMIK. "Perencanaan Strategi Sistem Informasi Pendidikan Pada Sekolah Tinggi Manajemen Informatika dan Komputer (STMIK) Lombok." Bianglala Informatika 3, no. 2 (2015).

[13] Imtihan, Khairul, and Muhamad Hasyim Basri. "SISTEM INFORMASI PEMBUATAN MANIFEST MUATAN KAPAL BERBASIS DEKSTOP DAN ANDROID." Jurnal Manajemen Informatika dan Sistem Informasi 2, no. 2 (2019): 69-76. 